\title{
Maintaining anencephalic babies causes consternation in USA
}

\section{San Francisco}

Loma Linda University Medical Center in southern California is preparing to implement a controversial new policy on anencephalic neonates (born with only a brain stem). The hospital will allow them to be maintained on a respirator so that their organs may be used for transplantation.

By US law, organs may not be taken from a living human being until it is legally brain dead. Many anencephalics are stillborn, but those born alive are allowed to die naturally. Brain-stem activity can persist for weeks or months, marked by periods of irregular breathing that deprive the organs of oxygen. This often means an anencephalic's organs have deteriorated too much to be used for transplants.

Although most adult organ donors usually accident victims - are on lifesupport systems before death, the life support is meant to be life-saving. With anencephalics, some now question the morality of using life support for the sole purpose of harvesting organs.

Some physicians and lawmakers want to change the legal definition of death to define anencephalics as brain dead at birth, so that their organs can be used immediately. But that proposal has sparked heated debate, with some saying that such a move would blur the line between life and death, paving the way for the use of organs from other critically ill patients, such as those in vegetative coma.

Arthur Caplan, director of the University of Minnesota Center for Biomedica Ethics, argues that no lines are blurred with anencephalics. They are unique, not because they are dying, he says, but because they have no higher brain function: no ability to feel, think or suffer.

Last January, Caplan proposed a compromise in which anencephalic children would be kept on a respirator to preserve their organs and, when their brain-stem function ceased, be used as sources of organs. Such a protocol was used in October by physicians at the University of Western Ontario, and provided a heart for a recipient at Loma Linda hospital.

Loma Linda, a leader in the field of neonatal heart transplants, has already shown a willingness to try new approaches to resolving the acute shortage of infant organ donors. In 1984, a medical team there used a baboon heart in a human infant.

Loma Linda will be the first hospital to implement a protocol for the maintenance of anencephalics in the United States. The first infant to be kept alive in the new protocol was to have been born earlier this week. The parents of the child learned about the fetus's condition three months ago, but chose to carry it to term in hopes of offering its organs for transplantation.

Loma Linda neonatologist Joyce Peabody, author of the hospital's new protocol, says that organ donation should be considered only when parents of anencephalic children decide on their own, without persuasion. The procedure will provide respectful treatment of the infant, including traditional provisions for comfort and pain relief, although anencephalics lack the capability to experience or interpret pain.

Because of the consensus that indefinite maintenance of an anencephalic would be

immoral, Loma Linda has adopted Caplan's suggestion that the infant be kept on a respirator for just seven days. If brain death occurs, as measured by periodic checks for cessation of spontaneous breathing, recipients will be sought for the child's heart, liver, corneas and possibly kidneys. After seven days, if the brain stem is still functioning or if organ recipients are not found, the child will be removed from the respirator.

To avoid the issue of conflict of interest, as Loma Linda is a transplant centre, Peabody said she would prefer that another hospital take on the case. However, that possibility is remote, and Loma Linda is ready to put its protocol into practice. Peabody pointed out that recipients can come from anywhere, and she hopes they will arise at sites other than Loma Linda, to simplify the hospital's role in the case.

Marcia Barinaga

\section{Drastic changes proposed for Australian higher education}

Sydney

Australia's new Minister for Employment, Education and Training, John Dawkins, has proposed dramatic changes to Australia's higher education system. His aim is to make its institutions, some of which he describes as ossified, serve national needs "flexibly and effectively".

The essence of the change can be summed up as "increased competition". If the Dawkins plan, presented in a 126page policy paper, wins approval, then the binary system, which separates the financing of universities and of colleges of advanced education, will be ended. All higher education institutions will have access to the same funds, while all university departments will no longer enjoy the right to resources for research.

Instead, institutions will have to bid for funds by presenting their "educational profiles" to the government, which will assess them for efficiency or effectiveness in terms of national priorities.

For funding purposes, student numbers will be assessed in terms of those who graduate rather than those who enrol. According to the policy paper, there has been an enormous waste of resources as a result of the high drop-out rates from the first years of courses.

As an initial step, it is planned that one per cent of funds in the 1988-91 triennium would be put into a pool for competitive allocation. Any institution which chose not to compete would simply lose a proportion, which will grow with time, of what it might otherwise expect.

Participating institutions, on the other hand, would also be freed from present government procedures for the approval of new courses and from rigid restrictions on staff pay scales. Institutions would be allowed to pay academics on the basis of merit and market conditions, with the understanding that in some disciplines staff would be paid more to prevent their defection to industry. Institutions would also have to devise means whereby incompetent or redundant staff could be sacked.

To achieve economies of scale, smaller institutions will be amalgamated. The minimum size for research institutions will be set at 8,000 students. A unified system of course accreditation and a common academic year will help staff and students move between institutions.

Dawkins hopes to increase the number of graduates from 88,000 a year at present to 125,000 per year in 2001 , a significant increase considering the smaller proportion of young people in the community by then. But he is in favour of those who benefit from education paying for it. Dawkins is likely to meet strong opposition to the reintroduction of fees from his Labor party colleagues who originally abolished them.

A spokesman for the association of university vice-chancellors was in favour of the removal of restrictions on institution's operations and freedom in staff remuneration, but wary of increased political intervention and, in particular, of the nature of the government's "educational profiles".

To the colleges of advanced education, the paper offers the opportunity finally to play a full role in higher education. A spokesman for the colleges' principals and directors described it as "one of the most significant junctures in the planning and provision of higher education in Australia". Charles Morgan 